\title{
Remediation of Sulfidic Wastewater by Aeration in the Presence of Ultrasonic Vibration
}

\author{
Farooq Ahmad \\ Department of Chemical and Material Engineering \\ College of Engineering, \\ Northern Border University \\ Arar, Saudi Arabia \\ Naveed Ahmad \\ Department of Chemical and Material Engineering \\ College of Engineering \\ Northern Border University \\ Arar, Saudi Arabia
}

\author{
Abdulaal Z. Al-Khazaal \\ Department of Chemical and Material Engineering \\ College of Engineering \\ Northern Border University \\ Arar, Saudi Arabia \\ Ibrahim Alenezi \\ Department of Chemical and Material Engineering, \\ College of Engineering \\ Northern Border University \\ Arar, Saudi Arabia
}

\begin{abstract}
In the current study, the aerial oxidation of sodium sulfide in the presence of ultrasonic vibration is investigated. Sulfide analysis was carried out by the methylene blue method. Sodium sulfide is oxidized to elemental sulfur in the presence of ultrasonic vibration. The influence of air flow rate, initial sodium sulfide concentration and ultrasonic vibration intensity on the oxidation of sodium sulfide was investigated. The rate law equation regarding the oxidation of sulfide was determined from the experimental data. The order of reaction with respect to sulfide and oxygen was found to be 0.36 and 0.67 respectively. The overall reaction followed nearly first order kinetics.
\end{abstract}

Keywords-aeration; sulfide oxidation; ultrasonic vibration; kinetics; remediation; environment; air flow rate

\section{INTRODUCTION}

Different processes are followed for the removal of sulfides, including wet scrubbing, liquid redox technology, biofiltration, scavengers, carbon adsorption, iron salts, biocide process, anthraquinone and use of oxidizing agents [1-4]. As documented in [1-9], sulfide removal from wastewater is mainly achieved by oxidation. Advanced oxidation is the latest among wastewater treatment techniques [1]. Oxidation can be accomplished chemically or biologically [10]. Chemical oxidation involves the removal of electrons and removal or addition of hydrogen [7]. In water and wastewater engineering, chemical oxidation serves the purpose of converting putrescible pollutant substances to innocuous or stabilized products [11]. Reserachers in $[9,12-16]$ investigated the oxidation of sulfides in the presence of catalyst, however, catalytic oxidation suffers from certain drawbacks and it is not economically suitable for large continuous treatment processes. Moreover, these catalysts are poisonous and hazardous and their complete recovery after treatment is essential. Photo oxidation in both presence and absence of catalyst has also been studied $[5,6,17,18]$. In the absence of catalyst, photo oxidation requires higher UV light intensity, which is not economically suitable for large continuous wastewater treatment processes $[17,18]$.

Authors in [13] investigated the sulfide oxidation by atmospheric oxygen in presence of "Sulfur Black B" dye as a catalyst. The reaction was reported to be first order in sulfide concentration. Authors in [11] made an exhaustive survey of the classical methods on sulfide oxidation. They carried out catalytic oxidation with dissolved oxygen using a number of catalysts including carbon black, ferric salts and a few organic compounds. Authors in [16] reported the effect of $\mathrm{FeCl}_{3}$ catalyst on the oxidation of $\mathrm{Na}_{2} \mathrm{~S}$ with dissolved oxygen. They analyzed the conversion data using a first order rate equation for sulfide removal. They found out that the rate constant is a function of $\mathrm{FeCl}_{3}$ concentration. Sulfide oxidation can be used for the synthesis of sulfones and sulfoxides. Authors in [14] indicate that the reaction of sulfides with $30 \%$ hydrogen peroxide catalyzed by tantalum (V) chloride in acetonitrile, ipropanol, or t-butanol produces high yields of sulfoxides. Authors in [19] developed the microbial fuel cell (MFC) for removal of sulfur-based pollutants. The fuel cell used activated carbon cloth and carbon fiber veil composite anode, air breathing dual cathodes and sulfate reducing species. In this system, most of the sulfide is electrochemically oxidized to sulfur.

\section{EXPERIMENTAL WORK}

\section{A. Analysis of Sulfide}

We prepared the test solution using sodium sulfide of $60 \%$ purity. Methylene Blue Method (MBM) [20] was used to analyze the sulfide, and estimated its concentration using DR 5000 Hach UV-visible spectrophotometer. Since elemental sulfur formation occurs during the oxidation process, carbon disulfide was added dropwise prior the analysis of sulfide for 
removing the elemental sulfur formed during the oxidation process.

\section{B. Methodology}

A schematic diagram of the oxidation process is shown in Figure 1. The reactor comprised of a glass reactor, ultrasonic vibrator, dissolved oxygen (DO) probe and spurger for distributing the air in the solution taken in the reactor. The ultrasonic vibrator was connected to the power supply. The DO probe was dipped into the liquid in the apparatus only to measure the dissolved oxygen concentration, and the $\mathrm{pH}$ probe monitored the solution's $\mathrm{pH}$. The glass reactor was dipped in the water inside the ultrasonic vibrator. The ultrasonic vibrator cannot be used as a reactor because in that case the temperature of the solution raises. The ultrasonic vibration is transferred into the solution inside the reactor through water present in the ultrasonic vibrator. Before the sulfide analysis, carbon disulfide was added in order to dissolve the elemental sulfur formed during the oxidation.

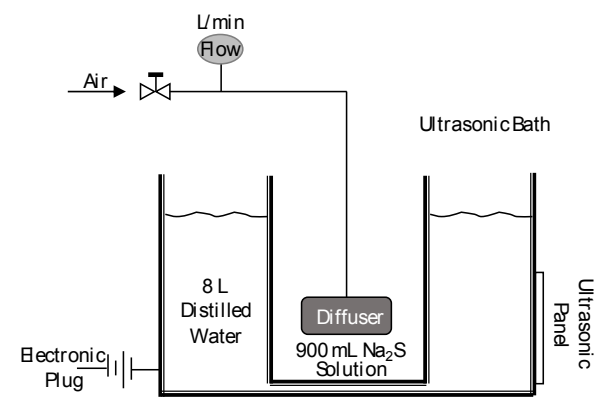

Fig. 1. Experimental set up for the sulfide oxidation in the presence of ultrasonic vibration.

\section{RESULTS AND DISCUSSION}

The aerial oxidation of sodium sulfide was investigated at different air flow rates, different initial sodium sulfide concentration and different ultrasonic vibration intensities. It was found that oxidation of sulfide produces elemental sulfur and sodium hydroxide. Initial $\mathrm{pH}$ of the sulfide solution was found to be 12 or more depending upon on the initial sulfide concentration. The $\mathrm{pH}$ of the solution increased gradually with an ultimate value equal to 13 which is alkaline $\mathrm{pH}$. The increase in the value of $\mathrm{pH}$ can be related to the liberation of caustic soda as a result of sulfide oxidation. The chemical reaction of sulfide and oxygen in the presence of ultrasonic vibration is the following:

$$
\mathrm{Na}_{2} \mathrm{~S}+\mathrm{O}_{2} \rightarrow 2 \mathrm{NaOH}+\mathrm{S}
$$

\section{A. Effect of Air Flow Rate}

The oxidation process was investigated at different air flow rates. It was found that the higher the atmospheric airflow rate at the opening of the spurger, the faster the sulfide oxidation. This is because higher atmospheric airflow rate at the opening of the spurger means larger concentration of oxygen in the liquid. The larger concentration of oxygen in the liquid will allow more reaction with the excited sulfide ions in the liquid. Increased reaction will shorten the time to oxidize the sulfides in the liquid. It was observed that the amount of dissolved oxygen remained constant during the oxidation while the $\mathrm{pH}$ of the liquid increased over time. This happened because during air bubbling, the oxygen from the air gets dissolved in the solution and the dissolved oxygen reacts with sulfide ions. Under a particular set of experimental conditions, the bubbling air supplied oxygen to the solution at a sufficiently high rate so that its concentration remained practically constant. The oxygen consumed by the sulfide ions was immediately replenished by absorption from the air bubbles. As sulfide was converted to elemental sulfur and sodium hydroxide, the $\mathrm{pH}$ increased up to 13. The effect of air flow rate on sulfide oxidation in the presence of ultrasonic vibration is shown in Figure 2.

\section{B. Effect of Initial Sulfide Concentration}

The oxidation process was also investigated at different initial sulfide concentration. It was observed that oxidation of $800 \mathrm{ppm}$ of sulfide took 50 minutes. The rate of oxidation was found higher at higher initial sulfide concentration. Increase in the initial sulfide concentration increased the time of sulfide oxidation. Oxidation of $1000 \mathrm{ppm}$ of sulfide took nearly 60 minutes. The airflow rate and ultrasonic vibration intensity were fixed, at 4 liter/minute and $100 \%$ respectively. From the experiment done using the experimental setup and process shown in Figure 1, the concentration of sulfides was decreased over time while the concentration of sulfur was increased over time. Oxidation of sulfide in the presence of ultrasonic vibration at different initial sulfide concentrations is shown in Figure 3. From this experiment, it is apparent that the process of removing sulfide ions from synthetic wastewater by means of reaction between sulfide ions and dissolved oxygen in the presence of ultrasonic vibration in wastewater is quite effective. Synthetic wastewater during treatment by aeration in the presence of ultrasonic vibration became turbid due to the formation of elemental sulfur. The turbidity of the solution was found higher at higher initial sulfide concentration indicating higher rate of formation of elemental sulfur at high sulfide concentration.

\section{Effect of Ultrasonic Vibration Intensity}

It was observed that at higher ultrasonic vibration intensity sulfide oxidation becomes faster. It may be related to the formation of larger amount of excited sulfide ions with the increase in the ultrasonic vibration intensity. The larger amount of excited sulfide ions in the liquid would allow more reaction with the oxygen and thus increased reaction that would shorten the time of the sulfides oxidation. The effect of ultrasonic vibration on sulfide oxidation is shown in Figure 4.

\section{Kinetics of Sulfide Oxidation in the Presence of Ultrasonic Vibration}

A power law rate equation for sulfide oxidation is proposed in [21]:

$$
r=K\left[P_{O_{2}}\right]^{m_{1}}\left[S^{-2}\right]^{m_{2}}
$$

where $\mathrm{K}$ is the rate constant, $\mathrm{m}_{1}$ and $\mathrm{m}_{2}$ are orders of reaction with respect to oxygen partial pressure and sulfide respectively. A plot of the rate of sulfide oxidation against initial sulfide 
concentrations on a logarithmic scale at a constant ultrasonic vibration gives the order $\mathrm{m}_{2}=0.36$. Thus the order of the reaction with respect to sulfide concentration is 0.36 . The reaction order with respect to oxygen was similarly found out by plotting the rate of sulfide oxidation against the initial oxygen partial pressure at different air flow rates on a logarithmic scale for constant values of all other parameters. The value of $m_{1}$ is 0.67 which is the order of the reaction with respect to oxygen partial pressure. Partial pressure of oxygen was calculated at different air flow rates using ideal gas equation. The reaction rate constant, $\mathrm{k}=0.55$ was determined from the slope of the plot of reaction rate against the product of two concentration terms in (2) as shown in Figure 5.

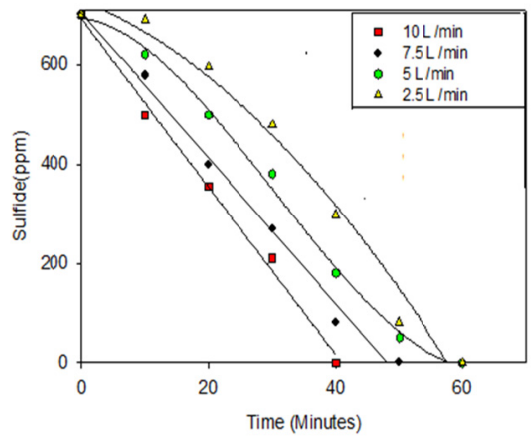

Fig. 2. Relationship between time and sulfide during oxidation at different air flow rates.

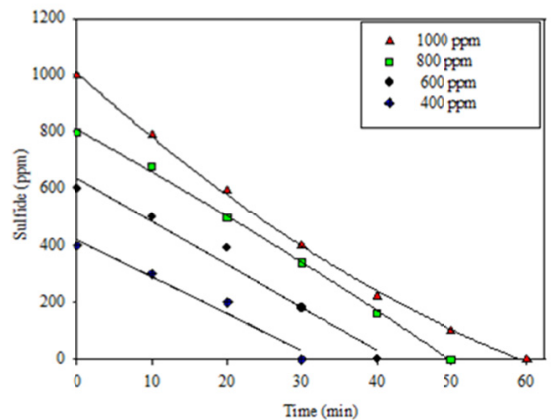

Fig. 3. Relationship between time and oxidized sulfide during oxidation at different initial sulfide concentrations.

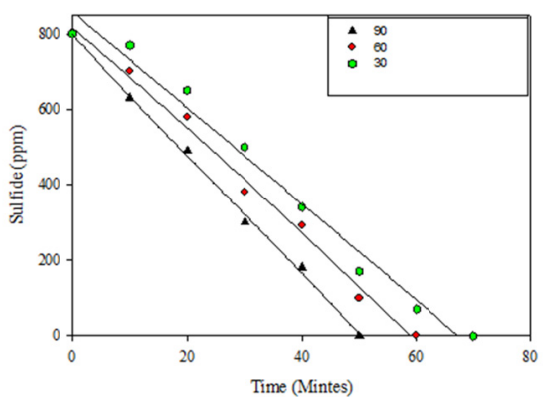

Fig. 4. Relationship between time and oxidized sulfide during oxidation at different sonication intensities.

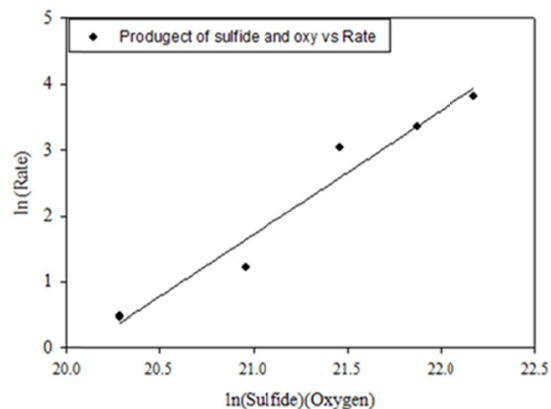

Fig. 5. Linear plot between the product of sulfide concentration and partial pressure of oxygen and rate of sulfide oxidation on logarithmic scale.

\section{CONCLUSION}

Sodium sulfide is removed from synthetic wastewater by aeration in the presence of ultrasonic vibration. Kinetics of aeration in the presence of ultrasonic vibration was investigated by air flow rate and sulfide concentration. The following conclusions can be drawn from the ultrasonic vibration oxidation: it was found that the rate of aeration of sulfide in the presence of ultrasonic vibration is faster at higher initial sulfide concentration, ultrasonic frequency and air flow rates. Complete removal of the sulfide from the wastewater is achieved by aeration in the presence of ultrasonic vibration. The overall oxidation followed mostly first order kinetics.

\section{REFERENCES}

[1] M. Ksibi, "Chemical oxidation with hydrogen peroxide for domestic wastewater treatment", Chemical Engineering Journal, Vol. 119, No. 2 3, pp. 161-165, 2006

[2] M. Seredych, T. J. Bandosz, "Adsorption of hydrogen sulfide on graphite derived materials modified by incorporation of nitrogen", Materials Chemistry and Physics, Vol. 113, No. 2-3, pp. 946-952, 2009.

[3] F. Ahmad, S. Maitra, N. Ahmad, "Treatment of Sulfidic Wastewater Using Iron Salts", Arabian Journal for Science and Engineering, Vol. 42, No. 4, pp. 1455-1462, 2017

[4] C. E. Ellis, "Wet Air Oxidation of Refmery Spent Caustic", Environmental Progress \& Sustainable Energy, Vol. 17, No. 1, pp. 2830, 1998

[5] W. Spiller, D. Wöhrle, G. Schulz-Ekloff, W. T. Ford, G. Schneider, J Stark, "Photo-oxidation of sodium sulfide by sulfonated phthalocyanines in oxygen-saturated aqueous solutions containing detergents or latexes", Journal of Photochemistry and Photobiology A: Chemistry, Vol. 95, No. 2, pp. 161-173, 1996

[6] C. A. Linkous, C. Huang, J. R. Fowler, "UV photochemical oxidation of aqueous sodium sulfide to produce hydrogen and sulfur", Journal of Photochemistry and Photobiology A: Chemistry, Vol. 168, No. 3, pp. $153-160,2004$

[7] R. Munter, "Advanced Oxidation Processes - Current status and prospects", Proceedings of the Estonian Academy of Sciences. Chemistry, Vol. 50, pp. 59-80, 2011

[8] J. G. Bain, D. W. Blowes, W. D. Robertson, E. O. Frind, "Modelling of sulfide oxidation with reactive transport at a mine drainage site", Journal of Contaminant Hydrology, Vol. 41, No. 1-2, pp. 23-47, 2000

[9] N. Ahmad, S. Maitra, B. K. Dutta, F. Ahmad, "Remediation of sulfidic wastewater by catalytic oxidation with hydrogen peroxide", Journal of Environmental Sciences, Vol. 21, No. 12, pp. 1735-1740, 2009

[10] [F. P. van der Zee, S. Villaverde, P. A. García, F. Fdz.-Polanco, "Sulfide removal by moderate oxygenation of anaerobic sludge environments", Bioresource Technology, Vol. 98, No. 3, pp. 518-524, 2007 
[11] Y. Ueno, A. Williams, "A New Method for Sodium Sulfide Removal From an Aqueous Solution and Application to Industrial WasteWater and Sludge", Water, Air, and Soil Pollution, Vol. 11, pp. 23-42, 1979

[12] N. Ahmad, F. Ahmad, I. Khan, A. D. Khan, "Studies on the Oxidative Removal of Sodium Thiosulfate from Aqueous Solution", Arabian Journal for Science and Engineering, Vol. 40, No. 2, pp. 289-293, 2014

[13] T. Sakai, K. Sawada, N. Ohi, "A Kinetic Study of Liquid-phase Oxidation of Sodium Sulfide with Oxygen Catalyzed by Rate of Gas flow", Journal of Chemical Engineering of Japan, Vol. 13, No. 4, pp. $331-334,1980$

[14] M. Kirihara, J. Yamamoto, T. Noguchi, Y. Hirai, "Selective synthesis of sulfoxides and sulfones by tantalum (V) catalyzed oxidation of sulfides with $30 \%$ hydrogen peroxide", Tetrahedron Letters, Vol. 50, No. 11, pp. 1180-1183, 2009

[15] P. K. Dutta, K. Rabaey, Z. Yuan, J. Keller, "Spontaneous electrochemical removal of aqueous sulfide", Water Research, Vol. 42, No. 20, pp. 4965-4975, 2008

[16] A. H. Nielsen, T. Hvitved-Jacobsen, J. Vollertsen, "Effects of Iron on Chemical Sulfide Oxidation in Wastewater from Sewer Networks", Journal of Environmental Engineering, Vol. 133, No. 6, pp. 655-658, 2007

[17] V. Iliev, A. Mihaylova, "Photooxidation of sodium sulfide and sodium thiosulfate under irradiation with visible light catalyzed by water soluble polynuclear phthalocyanine complexes", Journal of Photochemistry and Photobiology A: Chemistry, Vol. 149, No. 1-3, pp. 23-30, 2002

[18] N. K. Shammas, J. Y. Yang, P. C. Yuan, Y. T. Hung, "Photochemical treatment processes", in: Handbook of Environmental Engineering, 3rd Edition, Springer, pp. 229-270, 2007

[19] F. Zhao, N. Rahunen, J. R. Varcoe, A. J. Roberts, C. Avignone-Rossa, A. E. Thumser, R. C. T. Slade, "Factors affecting the performance of microbial fuel cells for sulfur pollutants removal", Biosensors and Bioelectronics, Vol. 24, No. 7, pp. 1931-1936, 2009

[20] D. Mallik, S. K. Chaudhuri, "Air Oxidation of Aqueous Sodium Sulfide", Water Research, Vol. 33, No. 2, pp. 585-590, 1999

[21] D. J. O'Brien, F. B. Birkner, "Kinetics of Oxygenation of Reduced Sulfur Species in Aqueous Solution", Environmental Science \& Technology, Vol. 11, No. 12, pp. 1114-1120, 1977 